\title{
La evolución de las revistas médicas
}

El 6 de marzo de 1665, durante la gran epidemia de peste bubónica y apenas unos meses antes que un voraz incendio destruyera en cuatro días infernales buena parte del centro de Londres, apareció el primer número de Philosophical Transactions, giving some Accompt of the present Undertakings, Studies, and Labours of the Ingenious in many considerable parts of the World, la revista científica más antigua del mundo y que sigue siendo hoy reconocida mundialmente, publicada en sus versiones $A$, dedicada a las ciencias físicas, y $B$, a las ciencias de la vida. Henry Oldenburg, primer secretario de la recientemente fundada Royal Society for the Improvement of Natural Knowledge, la financió de su bolsillo y la nutrió con resúmenes y transcripciones de las sesiones de dicha sociedad y con noticias y extractos de su nutrida correspondencia personal que mantenía con científicos y otras personas curiosas, de Inglaterra y de otros países. Vale la pena citar a algunos de los más conocidos, pues representan una medida del alcance de la revista: entre aquellos, a Newton, Hooke, Wren, Evelyn, Ashmole, Boyle y Thomas Browne; entre estos, a Malpighi, van Leeuwenhoek, Huygens, Spinoza, De Graaf, Jean Dominique Cassini.y Leibniz. Ese primer número tiene, entre otros, comunicados como A Spot in One of The Belts of Jupiter de Robert Hooke, dos de Robert Boyle, An Account of a very odd Monstrous Calf y An Experimental History of Cold, y también una estupenda reseña del reciente y magnífico libro del mencionado Hooke An Account of Micrographia, or the Physiological Descriptions of Minute Bodies, Made by Magnifying Glasses.

Esta primera revista tiene ya en sus orígenes, en su propósito y en su funcionamiento los mismos elementos de aquellas que irían apareciendo en el curso de los años, en particular, las científicas y, quizás con mayor similitud, las médicas. Trescientos cincuenta años después, las revistas científicas se cuentan en miles en el mundo; el aumento de los conocimientos médicos, del número de estos y su agrupación en sociedades o gremios, llevaron a la aparición de las primeras revistas médicas hacia fines del siglo XVIII, diferenciándose de sus precursoras en el ámbito general de las ciencias, pero las que han perdurado hasta nuestros días vieron la luz a principios del siglo XIX, por ejemplo, el Journal of the Royal Society of Medicine en 1809 y el New England Journal of Medicine (con otro nombre) en 1812, ambas representando y sirviendo al saber médico de la época y sus asociaciones. Luego, vendrían las de otras sociedades médicas que deseaban mostrar su quehacer y servir necesidades o intereses específicos, geográficos o disciplinarios. Aparecerían las de especialidades, luego las de subespecialidades y finalmente aquellas dedicadas a tópicos o intereses específicos como Advanced Materials o Nucleic Acids Research. Si bien todas nacieron iguales, algunas, las menos, han llegado a ser famosas e influyentes en todo el mundo, otras pocas lucen más de dos siglos de existencia, y algunas son ingentes negocios que han dado riquezas a las casas editoriales o a las organizaciones que las sustentan. Muchas más, sin embargo, son las que han desaparecido o luchan por sobrevivir en su alcance, influencia y economía. Como toda empresa, definida como acción o tarea que entraña dificultad y cuya ejecución requiere decisión y esfuerzo, toda revista requiere además, para completarse exitosamente, tiempo, talento, perseverancia y suerte. Como si la conjunción de todo lo anterior no fuese improbable, una revista solo termina por justificarse cuando consigue alinear el interés de lectores, autores y del medio en que está inmersa.

El pilar fundamental del éxito de una revista es la calidad de la información y de la argumentación que contiene y para ello es indispensable atraer las mejores contribuciones. Esto depende inicialmente del universo de posibles autores que la sustentan y de la calidad de la investigación y de la medicina que desarrollan. Probablemente, ninguno de estos factores es suficiente si no atrae publicaciones más allá de sus fronteras, cualesquiera que ellas sean, de la institución, de la sociedad científica o incluso, del país en que están insertas, dependiendo de la población y de su grado de desarrollo. Es fácil advertir que las revistas médicas más influyentes globalmente se publican en inglés y, por lejos en los Estados Unidos de Norteamérica y Gran Bretaña. En cambio, el alcance de aquellas publicadas en español no pasa de lo regional o nacional. Pero todas partieron con una aparición irregular y espaciada y pasaron dificultades de contenido y de financiamiento, llevando a muchas a fusionarse para sobrevivir. En la medida en que fueron alcanzando metas como la regularidad, un flujo suficiente de contribuciones de buena calidad, la diversificación del consejo editorial, de los pares evaluadores y de autores, fueron cimentando un prestigio creciente. Atraer a autores de otras latitudes representa 
un signo de crecimiento importante, y es de esperar que el hecho de que aproximadamente un tercio de las publicaciones en los últimos dos volúmenes provengan del extranjero sea un signo auspicioso de aquello.

Ars Medica tiene cimientos y una historia que en varios sentidos refleja la evolución de muchas. Nace y se desarrolla nutrida de ideales, ilusiones y esfuerzos de muchos. Heredera del Boletín de la Escuela de Medicina, con su énfasis en la educación continua, de Ars Medica antigua con su énfasis en los aspectos humanísticos de la medicina y de la salud, y de la Escuela de Medicina de la Pontificia Universidad Católica de Chile con su mandato fundacional de formar "médicos de ciencia y de conciencia". Como su nombre lo indica pretende alinear los intereses en torno a las dimensiones esenciales de la medicina que tan bien expresara Edmund D. Pellegrino, profesor emérito de Medicina y Ética Médica en Georgetown, quien escribió con belleza inigualable: "La medicina es la mas humana de las artes, la más científica de las humanidades y la más artística de las ciencias". Lograr reflejar y alinear estos intereses en el desarrollo de nuestra misión de "promover el conocimiento y la práctica de las distintas áreas y sub-disciplinas de la medicina resaltando sus implicancias en la sociedad actual" es un desafío grande y demandante. El grado en que lo alcancemos determinará el futuro de la revista como una que influye en su entorno o una que languidece, una que progresivamente irá aumentando su prestigio y su área de influencia o una que quedará limitada a su entorno inmediato. El desafío es grande y hay una misión que cumplir.

Jorge Dagnino Sepúlveda 